\title{
RR Variability in Acute Coronary Syndromes
}

\begin{abstract}
ADRIAN APOSTOL", CARINA BOGDAN", NICOLAE ALBULESCU*, MIRCEA IURCIUC, STELA IURCIUC, DANIEL LIGHEZAN, VLAD SABIN IVAN, DANA STOIAN, MIHAELA VIVIANA IVAN

Victor Babes University of Medicine and Pharmacy Timisoara, 2 Eftimie Murgu Sq., 30004, Timisoara, Romania

Heart rate variability $(H R V)$ is a simple measure that estimates cardiac autonomic modulation. Analysis in the time domain and frequency range of $R R$ variability suggests that the negative prognosis of patients with acute myocardial infarction is related to the overall neuro-vegetative imbalance. The alteration of $R R$ variability reflects the dysfunction of the autonomic nervous system and especially the reduction of parasympathetic tone. The results of this study confirm the association between the reduction of $R R$ variability and the increased risk of adverse events and mortality after acute myocardial infarction. Moreover, it appears that RR variability is an independent predictor for atrial fibrillation.
\end{abstract}

Keywords: RR variability, myocardial infarction, $H R V$, sudden cardiac death

RR variability is reduced in acute myocardial infarction, reduction related to the spread of coronary heart disease but independent of symptoms, left ventricular performance, history of myocardial infarction or localization of the infarction. The mechanism involved is considered to be the dysfunction of the autonomic nervous system. Whether this is a cause or a consequence in coronary heart disease is still a topic under debate. Acute ischemia results in decreased RR variability in all its components, and this decrease is directly correlated with left ventricular dysfunction, cytolytic peak (high sensitivity troponin, CK-MB) and Killip class.

Acute ischemia through its local changes, increases the risk of arrhythmia. Acute necrosis causes alteration of local electrical properties, acting at the cellular and regional level. Also, tissue mosaic creates the conditions for triggering lifethreatening arrhythmias. To this local condition is added the decrease of RR variability. The mechanism by which this decrease appears, implies, after some authors, the alteration of neural activity of cardiac origin. There are sympatheticsympathetic and sympathetic-parasympathetic reflexes triggered by the modification of the cardiac geometry due to the appearance of the non-contractile necrotic segments capable of causing the stimulation of the sympathetic terminations by mechanical distortion. This sympathetic excitation attenuates the vagal activity of the fibers that innervate the sinus node. Another explanation is the reduced response of renal cells to nerve modulation. As an expression of vagal tone, alteration of this property under acute ischemia conditions only manifests the arrhythmogenic potential of the ischemic myocardium.

Coronary ischemia lowers oxygen demand, lowers coronary flow, increases sympathetic tone and drastically lowers ventricular fibrillation threshold. Blocking sympathetic activity results in protection against malignant arrhythmias. Bilateral stellate ganglionectomy protects against arrhythmia through ischemia, instead favors reperfusion arrhythmia.

Heart rate fixity is a predictive factor of sudden coronary death, not influenced by the location of the infarction, left ventricular function, beta blocker treatment. Instead it is strongly influenced by age.

The decrease in RR variability after acute myocardial infarction is marked in the low frequency band, suggesting that in determining mortality, the balance between sympathetic and parasympathetic activity is more important than the simple decrease in vagal tone. The presence of alterations in the control of neurological mechanisms is also reflected in the day / night alterations. In the post-infarction period very small variations can be recorded in the very low frequency range (below $0.03 \mathrm{~Hz}$ ), with very small respiratory variations, as well as the diminished neurological modulated response of the target organ.

\section{Experimental part}

Materials and methods

The study comprised of 600 patients with myocardial infarction. From the total amount, 44 patients were excluded because of non-compliance, 40 patients had initial records with interferences and could not be correctly interpreted. There remained a number of 516 patients, from which 92 presented bundle branch block or non-specific intraventricular conduction delay. This study emphasis the characteristics of the patients without intraventricular conduction disorder. 
The diagnostic of acute myocardial infarction was established based on the standard criterion according to the 4th universal definition of acute myocardial infarction [1], using physical examination, electrocardiogram findings and cardiac markers, the diagnosis being positive when any two criteria were met. Patients received standard recommended treatment with beta-blockers, angiotensin-converting enzyme (ACE) inhibitors (ACEi), statins, calcium channel blockers in selected cases, anticoagulants, nitrates, 3-keto acetyl-thiolase-inhibitors [2], antiarrhythmics, antiplatelet agents and were addressed to cath-lab or received thrombolytic treatment in the 6-8hours time frame $[1,8,9]$.

The patients were evaluated with detailed medical history, physical examination, blood tests, standard electrocardiograms, RR variability and echocardiographic studies were obtained at admission, 1 month after discharge, every 3 months in the first year and every 6 months during a period of 5 years. All the mentioned parameters were evaluated for both survivors and deceased.

Electrocardiographic evaluation was performed using Hellige EA LR machine, software modulus LR that enables both heart beats detection and data download to a computer for off-line analysis. Statistical analyses were performed with available data analysis software (SPSS 10 for Windows, OpenEpi).

Using the electrocardiographic data, we were able to analyze the RR interval as well as time- and frequency-domain components of HRV and to perform statistical analysis. Standard statistical calculus included mean RR intervals (HRV), standard deviation of the RR interval (sd), standard deviation of all 5-minute mean RR intervals (SDANN5), standard deviation of all 5-minute mean RR intervals (SDMNN5), the root mean squared successive differences (SD/rMSSD), Ewing coefficient (BB50).

The parameters that were excluded from the calculus were the oscillations from atypical QRS complexes and from premature ventricular beats. To ensure no artifacts verification was also performed manually during recording.

Data sets of the HRV in the frequency domain were submitted to a rapid Fourier transformation algorithm in order to separate signal areas into high-frequency (RRIHF) $(0.15-0.5 \mathrm{~Hz})$ and low-frequency (RRILF) $(0.01-0.15 \mathrm{~Hz})$ bands (expressed in $\mathrm{ms}$ ). The spectrum of frequency variation is recorded on a 2 minute time frame [4,5].

To establish the sympathetic/parasympathetic balance we used the oscillating values from the frequency domain analysis, where the parasympathetic tone modulates the HRV with oscillations at the RRIHF and corresponds to the respiratory frequency and the RRILF reflects a combination of factors that include influences of both parasympathetic and sympathetic effects [4-7].

\section{Results and discussions}

From all the patients without intraventricular conduction disorders 99 patients died (23.34\%), where 11 of them succumbed because of a non-cardiologic cause. Table 1 depicts comparative results between survivors and diseased regarding characteristics of the late potentials, QRS complex and RMS40, RR variability, cardiac performance evaluated through left ventricle ejection fraction (LVEF), medication administered, complications and also arterial hypertension and diabetes mellitus incidence. One can observe from the analysis the significant statistical difference regarding the incidence of late potentials between the two groups, in the deaths group RMS40< $20 \mu \mathrm{V}$ was present at $94.85 \%$, while in the survivors group only in a proportion of $35.78 \%(\mathrm{p}=0.001)$, and a pathological QRS duration was observed in $61.85 \%$ of the deceased versus $27.21 \%$ of the survivors $(\mathrm{p}=0.0001)$. Moreover, this difference between the two groups (deceased and alive) was maintained at 1 year after the MI with $49.48 \%$ in the deceased group and $15.59 \%$ in the later $(\mathrm{p}=0.001)$.

Regarding the other risk stratification parameters there were statistically significant differences at a high level of significance: RR variability was low in patients who died compared to survivors, $93.81 \%$, versus $67.89 \%(p=0.001)$, a feature that remained constant after 1 year post-MI with $90.72 \%$ in the deceased group compared to $41.59 \%$ in those with favorable evolution. Regarding the ejection fraction the majority of the deceased presented at one point in time reduced LVEF $(90.72 \%)$, while only $2.75 \%$ of the 5-year survivors presented reduced cardiac performance. The majority of the latter had an ejection fraction between $41-55 \%$ (45.87\%) and above.

In the particular situation of myocardial infarction, we have to take into account structural changes $[7,10,11]$ which determine different electrical and mechanical behavior in a highly inflammatory response and in different co-morbidities $[3,6,11,12,13]$. RR variability alterations and the presence of late potentials as marker of re-entry and electrical inhomogeneity would manifest themselves as risk, arrhythmia and heart failure due to specific changes in homeostasis in co-morbidities and might be potentiated by medication [2, 14-16]. 
Table 1

COMPARATIVE RESULTS BETWEEN SURVIVORS AND DECEASED

\begin{tabular}{|c|c|c|c|}
\hline & Dead n1=99 & Survivors $\mathrm{n} 2=325$ & $\mathrm{P}$ \\
\hline RMS40 at admission & $92(94.85 \%)$ & $117(35.87 \%)$ & 0.001 \\
\hline RMS40 at 1 year & $48(49.48 \%)$ & $51(15.59 \%)$ & 0.001 \\
\hline QRS at admission & $60(61.85 \%)$ & $89(27.21 \%)$ & 0.0001 \\
\hline RR Variability at admission & $91(93.81 \%)$ & $222(67.89 \%)$ & 0.001 \\
\hline RR Variability at 1 year & $88(90.72 \%)$ & $136(41.59 \%)$ & 0.001 \\
\hline LV ejection fraction $0-40 \%$ & $88(90.72 \%)$ & $9(2.75 \%)$ & 0.001 \\
\hline $41-55 \%$ & $5(5.15 \%)$ & $150(45.87 \%)$ & 0.001 \\
\hline$>56 \%$ & $4(4.13 \%)$ & $168(51.38 \%)$ & 0.001 \\
\hline Chronic heart failure & $68(70,1 \%)$ & $77(23.55 \%)$ & 0.001 \\
\hline Arrhythmias & $60(61.86 \%)$ & $38(11.62 \%)$ & 0.00001 \\
\hline Atrial fibrillation & $23(23.71 \%)$ & $33(10.09 \%)$ & 0.0005 \\
\hline Recurrent infarction & $9(9.28 \%)$ & $18(5.5 \%)$ & 0.181314 \\
\hline Residual angina & $48(49.48 \%)$ & $101(30.89 \%)$ & 0.000753 \\
\hline Thrombolysis & $27(27.84 \%)$ & $167(51.07 \%)$ & 0.000055 \\
\hline Beta blockers & $77(79.38 \%)$ & $288(88.07 \%)$ & 0.029845 \\
\hline ACEi & $80(82.47 \%)$ & $271(82.87 \%)$ & 0.926912 \\
\hline Trimetazidine & $30(30.93 \%)$ & $168(51.38 \%)$ & 0.000393 \\
\hline Amiodarone & $22(22.68 \%)$ & $33(10.09 \%)$ & 0.0011 \\
\hline Diabetes mellitus & $45(43.39 \%)$ & $94(28.75 \%)$ & 0.007004 \\
\hline Arterial hypertension & $64(65.98 \%)$ & $163(49.85 \%)$ & 0.005148 \\
\hline
\end{tabular}

Kaplan Meier survival curves exhibit the association between the impaired RR variability expressing vegetative alteration and a 3 -fold increased risk of cardiac death. (figure 1)

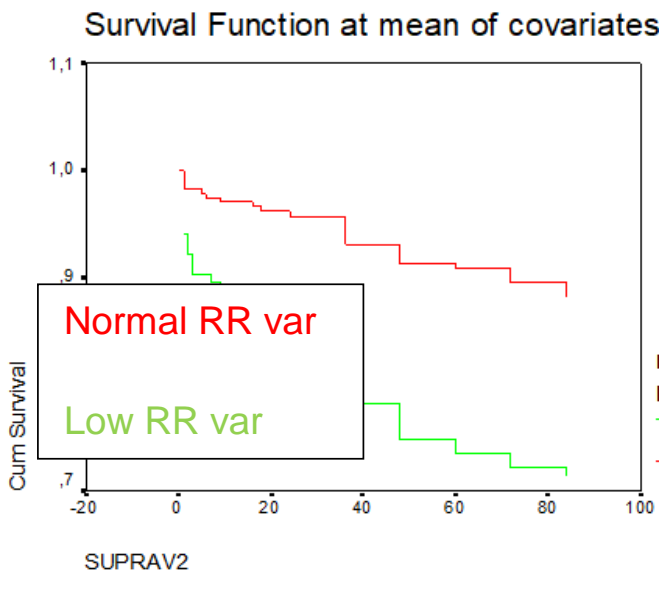

Fig. 1 Kaplan Meier survival curves

The variation of sd in survivors and in the deceased was less extensive compared to the other parameters, which suggests that the risk of sudden cardiac death is less related to the parameters that measure the parasympathetic tone. 
Other evidence in this regard is provided by the frequency domain analysis. The high frequency component that corresponds to the respiratory rate and primarily reflects the parasympathetic tone correlates with the sd parameters in the time domain. The fluctuations of the low frequency components were more emphasized in the group of deaths compared to the survivors. $(\mathrm{P}=0.00361)$. Although both high- and low-frequency components are low in the post-acute myocardial infarction period, the differences were more blurred in the high-frequency band.

For the prognostic assessment, the vegetative balance is important and not only the vagal tone. The importance of this balance is also illustrated by the reduction of the low frequency / high frequency ratio in patients with acute myocardial infarction.

The correlation of not only late potentials but also of the reduced vagal tone with the overall neuro-vegetative imbalance contributes to the increase in sudden cardiac arrest triggered by life-threatening ventricular arrhythmias. The method of evaluating the neuro-vegetative imbalance we applied was to determine the RR variability in both the time domain and the frequency domain.

The results of this study confirm the association between the reduction of RR variability and the increased mortality after acute myocardial infarction. Analysis in the time domain and frequency range of RR variability suggests that the negative prognosis of patients with acute myocardial infarction is related to sympathetic-parasympathetic balance and is not exclusively determined by vagal tone. The alteration of RR variability reflects the dysfunction of the autonomic nervous system and especially the reduction of parasympathetic tone. (Table 2).

Table 2

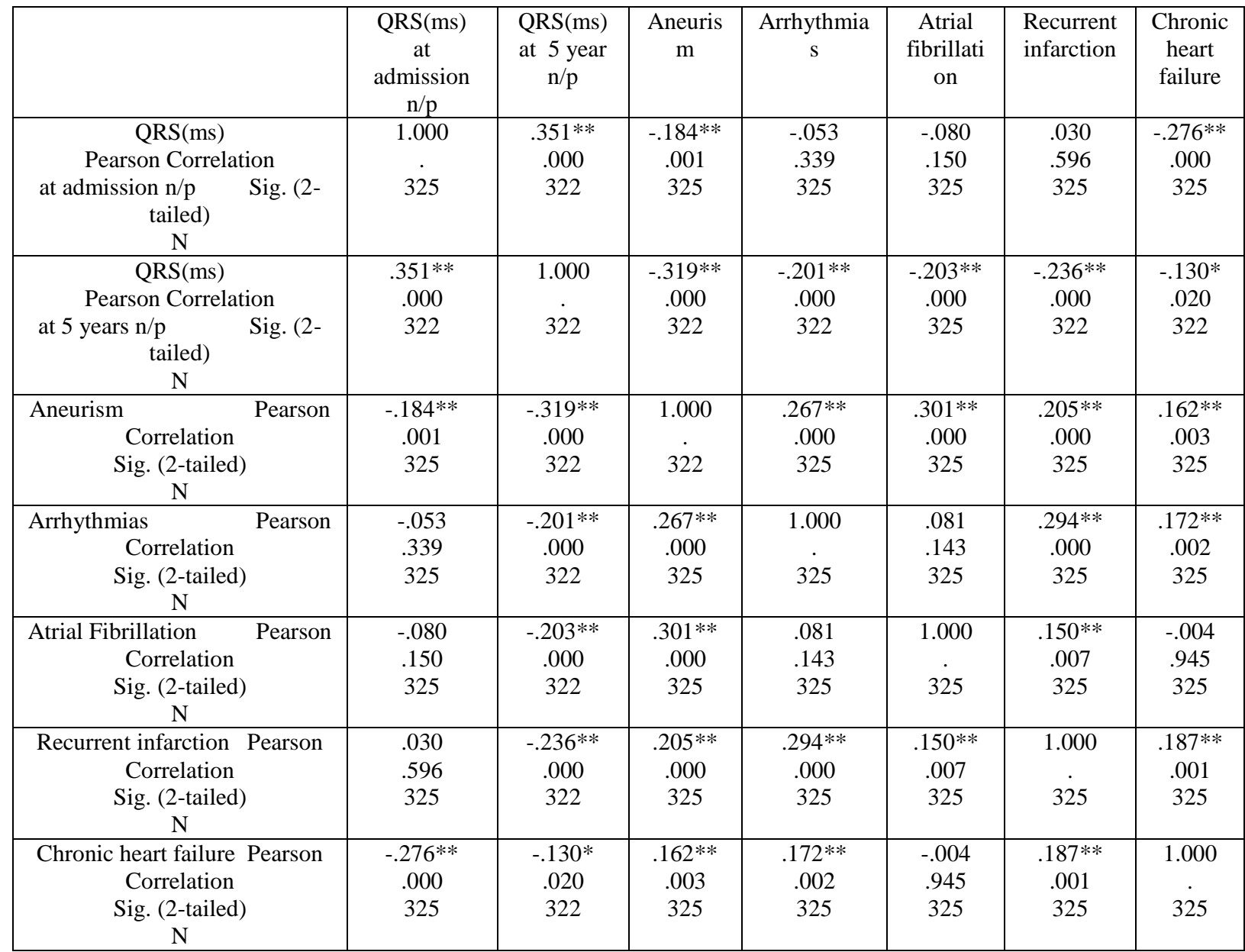

*Correlation is significant at the 0.05 level (2-tailed)

** Correlation is significant at the 0.01 level (2-tailed).

Development of atrial fibrillation after infarction represents the expression of a hemodynamic alteration and is closely correlated with the size of the infarction $[6,8,9,16]$. The identification of patients at risk of developing atrial fibrillation allows the identification of the group of patients in whom the hemodynamic impact of the infarction is greater and more difficult to control. In our study group, during the 5 years follow-up, a number of 110 patients $(21.31 \%)$ developed atrial fibrillation. Of these, 46 died before 5 years and 64 survived. Table 3 depicts comparative data between patients with and without atrial fibrillation. 
Table 3

AFib PATIENT CHARACTERISTICS

\begin{tabular}{|c|c|c|c|}
\hline & Patients with Atrial fib & Patients without atrial fib & $\mathrm{p}$ \\
\hline Total & $110(21.31 \%)$ & $406(79,68 \%)$ & 0.782 \\
\hline Age & $62 \pm 4$ & $61 \pm 5$ & 0.048 \\
\hline Women & $46.4 \%$ & $32.6 \%$ & 0.893 \\
\hline Anterior MI & $62.4 \%$ & $63.8 \%$ & 0.463 \\
\hline Inferior MI & $37.5 \%$ & $36.1 \%$ & 0.000271 \\
\hline RR var sd & $19 \pm 3 \mathrm{~ms}$ & $37 \pm 11 \mathrm{~ms}$ & 0.0039 \\
\hline EF & $0.38 \pm 0.04$ & $0.44 \pm 0.09$ & 0.052 \\
\hline Diabetes & $38.9 \%$ & $40.5 \%$ & 0.094 \\
\hline High BP & $49.2 \%$ & $47.8 \%$ & 0.00367 \\
\hline Deaths & $41.81 \%$ & $23.34 \%$ & \\
\hline
\end{tabular}

Therefore, as shown in the table, the patients who developed atrial fibrillation were usually women (at the limit of statistical significance $p=0.048)$, had low RR variability at an extremely statistically significant level $(p=0.000271)$, with a lower ejection fraction $(\mathrm{p}=0.0039)$. There were no statistically significant differences in age, location of infarction, association of diabetes or hypertensive disease. Moreover, if we take into account the ejection fraction in atrial fibrillation, it appears that RR variability is an independent predictor for atrial fibrillation.

\section{Conclusions}

RR variability represents an expression of neuro-vegetative imbalance, an alteration of the balance of sympathetic and parasympathetic activity. Reducing RR variability means reducing parasympathetic tone but also the presence of parasympathetic/sympathetic imbalance.

The sympathetic-parasympathetic imbalance is in close correlation with the electrical vulnerability of the myocardium, the patients presenting an increased risk of negative cardiac events and sudden death. The variability of RR with its components is a predictive factor of sudden coronary death.

Mortality due to life-threatening arrhythmias was higher in patients with low RR, who are electrically vulnerable to ischemic myocardium. They showed a marked alteration of all the variability parameters evaluated in the time domain or in the frequency domain. Also, alteration of the vegetative balance increases the risk of developing atrial fibrillation, which exposes patients to higher mortality compared to those in sinus rhythm. Patients who developed atrial fibrillation had low RR variability and a lower ejection fraction.

\section{References}

1.THYGESEN K, ALPERT JS, JAFFE AS, CHAITMAN BR ET AL. Task Force fourth Universal Definition of Myocardial Infarction - European Heart Journal (2019) 40, 237-269

2.IVAN MV, GEORGESCU M, APOSTOL A, ALBULESCU N, SERB AF, TATU CS - Trimetazidine, a Metabolic Modulator, with Cardioprotective Effects Against Myocardial Ischemia. Rev.Chim. (Bucharest) 69 no 7, 2018 p.1616.

3.COSENTINO F, GRANT PJ, ABOYANS V, ET AL. ESC Scientific Document Group, 2019 ESC Guidelines on diabetes, pre-diabetes, and cardiovascular diseases developed in collaboration with the EASD: The Task Force for diabetes, pre-diabetes, and cardiovascular diseases of the European Society of Cardiology (ESC) and the European Association for the Study of Diabetes (EASD), European Heart Journal, ehz 486.

4.ALBULESCU N, IVAN VS, APOSTOL A, IOVANESCU G, IVAN MV, SCHILLER A. Cardiac Electrical Vulnerability after Acute Myocardial Infarction Associated with Respiratory Infections. Rev. Chim. (Bucharest), 70 no. 1, 2019, p. 207-210

5.TURER AT, ADDO TA, MARTIN JL ET AL. Myocardial ischemia induced byrapid atrial pacing causes troponin T release detectable by a highly sensitive assay: Insights from a coronary sinus sampling study. J Am CollCardiol2011; 57:2398-2405.

6.SARKISIAN L, SAABY L, POULSEN TS ET AL. Clinical characteristics and outcomes of patients with myocardial infarction, myocardial injury, and non-elevated troponins. Am J Med 2016; 129:446e.5-446e.21.

7.FALK E, NAKANO M, BENTZON JF ET AL. Update on acute coronary syndromes: The pathologists' view. Eur Heart J 2013; 34:719-728.

8IBANEZ B, JAMES S, AGEWALL S ET AL. 2017 ESC Guidelines for the management of acute myocardial infarction in patients presenting with ST-segment elevation. Eur Heart J 2018; 39:119-177.

9.ROFFI M, PATRONO C, COLLET JP ET AL. 2015 ESC Guidelines for the management of acute coronary syndromes in patients presenting without persistent ST-segment elevation. Eur Heart J 2016; 37:267-315.

10. LIGHEZAN R, STURZA A, DUICU OM, R, CEAUSU RA, VADUVA A, GASPA M, FEIER H, VAIDA M, IVAN V, LIGHEZAN D, MUNTEAN DM, MORNOS C - Monoamine oxidase inhibition improves vascular function in mammary arteries from nondiabetic and diabetic patients with coronary heart disease - CANADIAN JOURNAL OF PHYSIOLOGY AND PHARMACOLOGY oct 2016 Volume: 94 Issue: 10 Pages: 1040-1047

11.IVAN VS, ALBULESCU N, ALBULESCU IR, APOSTOL A, BUZAS R, SCHILLER A, TIMAR R, LIGHEZAN D, IVAN MV. Predictive Value of Several Echo Parameters for Cardiovascular Events in Hemodialysis Patients with Mid-range and Preserved Ejection Fraction Heart Failure. Rev. Chim. (Bucharest), 70, no. 4, 2019, p.1479-1484

12.IVAN MV, ROGOBETE A, BEDREAG O ET AL. - New Molecular and Epigenetic Expressions as Novel Biomarkers in Critically Ill Polytrauma Patients with Acute Kidney Injury (AKI), Clinical Laboratory, volume:64 Issue:5, pg 663-668. 
13.ROGOBETE AF, SANDESC D, BEDREAG OH, PAPURICA M, POPOVICI SE, BRATU T, POPOIU CM, NITU R, DRAGOMIR T, AABED HIM, IVAN MV. MicroRNA Expression is Associated with Sepsis Disorders in Critically Ill Polytrauma Patients. Cells. 2018;7(12):271. Published 2018 Dec 13.

14.MUNTEANU, M., APOSTOL, A., IVAN, M.V., New Considerations Regarding Chronic Kidney Disease, Cardiovascular Disease and Dyslipidemia in Diabetic Patients. Rev. Chim. (Bucharest), 69 no 8, 2018, p. 2064.

15.APOSTOL A, CHISAVU L, ALBULESCU N, STOIAN D, SCHILLER A- RAS Inhibition in Hemodialysis Patients Impact on mortality; Rev. Chim. (Bucharest) 70 no 2, 2019, p. 442-444

16.ALBUlESCU N, APOSTOL A, ALBUlESCU IR, MIHAESCU A, SCHILlER A, TIMAR R., Furosemide Pharmacodynamics and Cardiovascular Effects in Hemodialysis Patients - Rev.Chim. (Bucharest) 70 no 3, 2019, p. 973-976

17.CHAPMAN AR, SHAH ASV, LEE KK, ANAND A, FRANCIS O, ADAMSON P, MCALLISTER DA, STRACHAN F, NEWBY DE, MILLS NL. Long term outcomes in patients with type 2 myocardial infarction and myocardial injury. Circulation 2018;137: 1236-1245.

Manuscript received: 19.12 .2019 